\title{
Runoff and salt transport modelling to maximise environmental outcomes in the upper south east of South Australia
}

\author{
$\underline{\text { M.S. Gibbs }}{ }^{\text {abb }}$, H.R. Maier ${ }^{a}$ and G.C. Dandy ${ }^{a}$ \\ ${ }^{a}$ WaterSYSTEMS group, School of Civil, Environmental and Mining Engineering, The University of \\ Adelaide, Adelaide, South Australia. \\ ${ }^{b}$ Science, Monitoring and Information Division, Department for Water, Government of South \\ Australia \\ Email: mgibbs@civeng.adelaide.edu.au
}

\begin{abstract}
Water resource management often requires an integrated assessment of resource use options, including local and regional impacts on the environment and stakeholders. The Upper South East of South Australia is one such location, where a large drainage network has been constructed to manage flooding, dryland salinity and environmental outcomes. Within the drainage network, there are a number of regulators that enable water to be directed along different natural watercourses or drainage paths to meet management objectives. Given the recent dry period, there is a desire to manage the limited water available to maximise the ecosystem response at the many wetlands in the region. This paper describes the methodology undertaken to assist the planning of regulator settings within the drainage network for an upcoming water year.
\end{abstract}

Coupled component models have been used to assess the outcomes expected for different regulator operating regimes. A hydrologic model representing the 1 million ha contributing to the drainage network was used to calculate the runoff expected from each catchment, as well as the movement of this water through the drainage network and into the wetland systems. The outputs from the hydrologic model, including catchment surface flows, baseflows, and wetland storage volumes were used as inputs to a water quality model, simulating the transport of salt at the catchment scale through the system. The hydrologic model and water quality model are ultimately used to produce relationships between the winter rainfall and the volume that can be delivered to target wetlands in the network, for a range of maximum salinity thresholds.

There are uncertainties in each step of the coupled component modelling procedure. One large source of uncertainty is the climate for the upcoming year is unknown. This will obviously impact the water available for environmental purposes. Secondly, the groundwater salinity, required as an input for salt transport modelling, is sparsely gauged in space and time in the region. A 20 year period has been simulated to represent a range of climate inputs to the model, and various values of groundwater salinity have been considered to provide an indication of the impact these uncertainties have on the simulated volumes.

A total of 128 regulator settings were considered to determine the configuration that can maximise the volume of water delivered to each target wetland for a range of maximum salinity thresholds. It was found that the optimal regulator settings were largely insensitive to the variability in the climate or groundwater salinities, with the same groups of settings identified as performing the best for each target wetland. The most upstream regulators were also found to have little impact on the volume of water available at the most downstream target wetlands, and hence the upstream regulators could be set to satisfy the requirements of the closest target wetlands. However, the downstream target wetlands were in competition with each other for the water resource, and therefore these regulators must be set based on the highest water requirement in a given year.

Relationships were derived between the driving rainfall variable and the volume available at each target wetland, for a range of maximum salinity thresholds. This information can be used to determine the likelihood of meeting environmental objectives in the region, based on a forecast of the winter rainfall for the upcoming year. This work highlights the importance of keeping the modelling objectives in mind when considering the outputs and uncertainties involved in integrated modelling assessment.

Keywords: Rainfall - runoff modelling, salinity, uncertainty, water quality, water resources management. 


\section{INTRODUCTION}

Water resource management often requires an integrated assessment of resource use options, including local and regional impacts on the environment and stakeholders (Croke et al., 2007). Often, it is not only the quantity of the resource that is limiting, but the quality of the water may also restrict where the resource is suitable for use. Generally, more attention has been paid to estimating the quantity of a water resource, generally through the use of rainfall - runoff models, compared to the associated water quality, which, in many cases, is just as important when assessing water resource management options.

One water quality measure that is often of interest is salinity. Salinisation is a major global environmental phenomenon which has already significantly degraded many water resources, and will continue to do so, but has received very little international attention (Department for Water, 2010). Water resource managers in Australia have relatively few tools to assist them in assessing the risk of the adverse effects of future salinity increases, or minimizing these risks (James et al., 2003). In order to manage altered hydrology and salinity regimes and minimize the impact of increasing salinity on the regional landscape, managers need information to aid their decision-making. Unfortunately, the information to support these decisions is inadequate at present (James et al., 2003).

Further compounding the issue is that there are large uncertainties associated with the information that is available to support decision making in water resource management. One reason for the focus on water quantity modelling over water quality modelling is that errors in outputs of the quantity models transfer to inputs in the quality models, which in turn have their own uncertainties. This paper considers the management of a water resource to support the ecology of remnant wetlands, where both the water quantity and quality are important to meeting the environmental water requirements (EWR). A case study in the Upper South East of South Australia has been considered. The impact of some of the uncertainties in the inputs to the water quality model on the ability to meet EWRs is assessed, along with the implications for management in the region.

\section{CASE STUDY REGION - UPPER SOUTH EAST OF SOUTH AUSTRALIA}

The case study considered is the Upper South East (USE) of South Australia (Figure 1), which covers over 1 million ha, and contains the largest area affected by dryland salinity in South Australia, estimated to be $40 \%$ of the region. There are an estimated $2,515 \mathrm{~km}$ of drainage channels removing surface water, controlling saline groundwater levels and improving regional agricultural productivity. This significant change in landuse and hydrology has impacted upon the ecology of the remaining wetlands, with a decrease in wetland area from $47 \%$ of the South East to only $6 \%$ of the initial areal extent, and of these only $10 \%$ are predicted to be in good ecological condition (Department for Water, 2010). Hence, there is a need to ensure the protection of the remaining wetlands, however the impacts the drains on the hydrological regime and water quality (in terms of salinity) are poorly understood (Gibbs et al., 2008).

\section{DRAINAGE NETWORK MANAGEMENT MODEL}

Management of the regulators in the drainage network to maximize the benefit to the wetlands in the region is a difficult task. In this work water quantity has been estimated using a rainfall - runoff model and water quality estimated using a salt transport model. While there are uncertainties in all aspects of the modelling, the impact the uncertainties in the inputs to the salt transport model have on the simulated results has also been considered.

\subsection{Hydrologic Model}

The Soil Moisture Accounting (SMA) loss model available in the HEC-HMS software package has been used with a daily time step in this work. The conceptual model allows for loss from the groundwater storage to an unconfined aquifer, which other conceptual models more commonly used in Australia (such as AWBM or SIMHYD) do not. A multi-objective Genetic Algorithm was used to calibrate the model to the few gauged and unregulated catchments in the region, and a regionalization approach was developed to provide a model of the whole region, achieving Nash-Sutcliffe efficiency values of approximately 0.7 for the catchments considered (Gibbs et al., 2010, Gibbs et al., 2011).

The Muskingum - Cunge routing method has been used to represent the drainage network, as it can represent the attenuation of flood waves and backwater effects (provided they remain within the same reach element) and can be parameterised directly from the channel geometry, length, slope and Manning's n roughness. Channel and wetland losses were initially parameterised using the soil saturated hydraulic conductivity, 


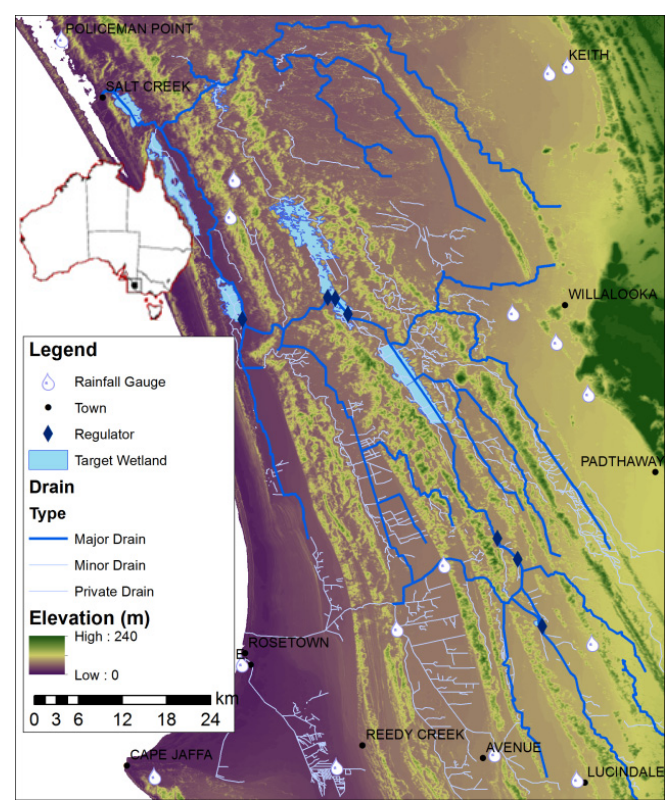

Figure 1 Map of USE region.

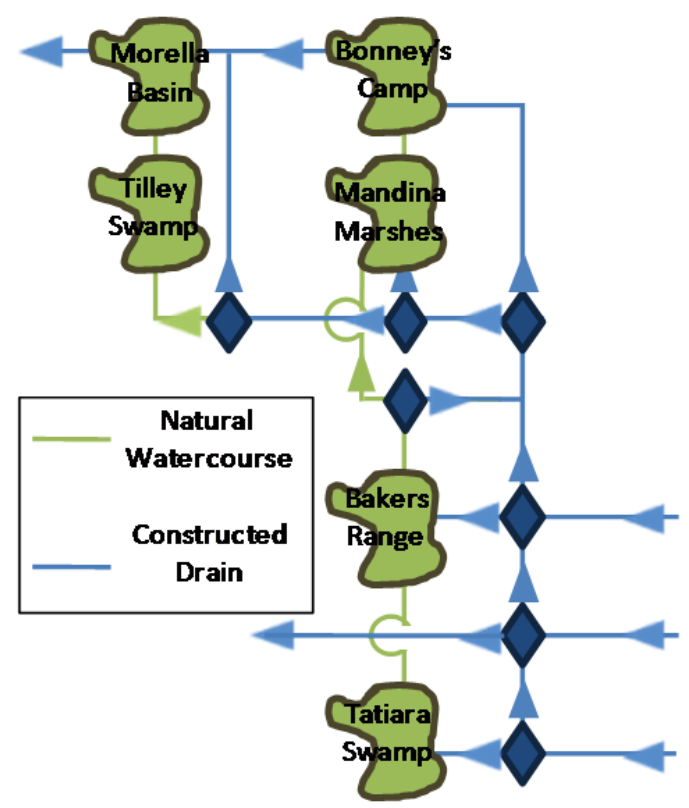

Figure 2. Schematic of regulators and target wetlands.

followed by manual adjustment based on observations at upstream gauges of flow and wetland depth, where available. Wetland storage - area volume relationships were derived from the $2 \mathrm{~m}$ Digital Elevation Model (DEM) of the region. The DEM was acquired in the summer of 2007/2008, when there was very little water in the landscape to allow full bathymetry of wetlands to be captured. Full supply levels for each wetland were determined from the DEM based on imagery and knowledge of flow paths in the region. As validation, surveys were undertaken in Morella basin to compare the derived relationships.

\subsection{Salt Transport Model}

Each EWR specifies depth of water in the target wetland for different months of the year, as well as an acceptable salinity of that water. Hence, the CATSALT model has been implemented to estimate the water quality along with the rainfall runoff model to estimate water quantity. CATSALT is a quasi-physical model developed to couple landscape salinisation and stream salinity (Tuteja et al., 2003). The salt mobilisation and washoff components of the model have been coupled with the HEC-HMS runoff model to estimate the catchment salt transport. The CATSALT model was originally developed to assess the impact of land use change on salt mobilisation, and contained components for the runoff from different land uses. This is not of concern for this study, in which case the simplified salt transport equations for the soil component can be written as $Q_{\text {salt }}^{r}(t)=\gamma\left(Q^{r}(t)\left(\frac{C_{s}}{K_{F}}\right)^{\frac{1}{\alpha}}+Q^{r} C_{\text {rain }}\right)$, and groundwater component as $Q_{\text {salt }}^{g}(t)=\gamma \beta C_{g} Q^{g}(t)$ (Coff et al., 2009). In this case, $Q_{\text {salt }}^{r}(t)$ and $Q_{\text {salt }}^{g}(t)$ are the salts entering the stream with surface runoff and groundwater discharge (tonnes/d), respectively, $\mathrm{Q}^{\mathrm{r}}(\mathrm{t})$ and $\mathrm{Q}^{\mathrm{g}}(\mathrm{t})$ are the components of flow from overland and groundwater contributions $\left(\mathrm{m}^{3} / \mathrm{s}\right)$ for time $\mathrm{t}$ (days), respectively, $\mathrm{C}_{\mathrm{s}}, \mathrm{C}_{\text {rain }}$ and $\mathrm{C}_{\mathrm{g}}$ are the soil, rainfall and groundwater salinities $(\mathrm{mg} / \mathrm{L})$, respectively, $\gamma$ is a unit conversion factor $(0.0864), K_{F}$ is the Freundlich constant $\left(\mathrm{m}^{3} / \mathrm{kg}\right), \alpha$ is a measure of non-linearity of the sorptive exchange process of the soil, and $\beta$ is a parameter representing the hydraulic contact between the aquifer and the stream. $C_{\text {rain }}=0$ has been assumed.

Four catchments with daily flow and salinity records of lengths between 3 and 12 years were used to calibrate the three CATSALT parameters $\left(\mathrm{K}_{\mathrm{F}}, \alpha\right.$ and $\left.\beta\right)$. Average groundwater salinities were adopted for each catchment, weighted spatially across groundwater observation wells using a Thiessen polygon approach and averaged temporally over the time period coinciding with the flow and stream salinity records. Soil salinities were adopted based on the SA Soil and Land Use Database (Department of Water Land and Biodiversity Conservation, 2002). A Monte Carlo simulation approach was used to assess the uncertainty in the parameter values, where 20,000 samples were taken uniformly over the ranges $1 \leq \mathrm{K}_{\mathrm{F}} \leq 10,0.1 \leq \alpha \leq 1.5$ and $0.1 \leq \beta \leq$ 0.95 . The best $5 \%$ of parameter combinations, as assessed by the Root Mean Squared error (RMSE) across the four catchments concurrently, were further investigated to assess the parameter identifiability of the salinity model. All of the best performing parameter combinations contained $\beta=0.7$, hence this value has been adopted across the region. There was a strong correlation between $\mathrm{K}_{\mathrm{F}}$ and $\alpha$, as both parameters operate 
on $\mathrm{C}_{\mathrm{s}}$. Also, $\mathrm{K}_{\mathrm{F}}$ and $\alpha$ were generally found to be insignificant, as groundwater salinity is the main source of salts entering the stream for a large proportion of the region (hence $\mathrm{C}_{\mathrm{s}} \approx 0 \mathrm{mg} / \mathrm{L}$ ). Values of $\mathrm{K}_{\mathrm{F}}=1$ and $\alpha=$ 0.9 were adopted, as they produced the best model performance overall, and the model was found to be insensitive to these parameters. Using observed flows for the inputs to the CATSALT equations, salt loads were simulated with $\mathrm{R}^{2}$ values in the range $0.7-0.9$ across the four catchments.

The CATSALT model allowed the salinity of the catchment runoff to be estimated. In order to be able to implement a salt transport model across the drainage network, complete mixing was assumed in each routing (drain) and storage (wetland) element of the hydrologic model. A daily time step weighted mass balance was implemented for the storage elements, where the volume of inflows and the volume in storage were used to update the salinity in the wetland, before the volume of water lost to evaporation for that day was used to increase the wetland salinity, assuming the salinity of the evaporated water was zero. This approach allowed evapoconcentration effects to be simulated, however, more complex processes, such salt deposition or accumulation in the soil, were not considered.

\subsection{Uncertainty Analysis}

The uncertainty in the inputs to the salt transport model has been considered in order to quantify its impact on simulated water quality. In the context of managing the regulator setting for environmental benefits, the greatest uncertainties are in the climate, where the amount and timing of upcoming winter rainfall is unknown, as well as the quality of any runoff, driven largely by groundwater salinity. Since 1990, the average annual rainfall of $600 \mathrm{~mm}$ has ranged from $400 \mathrm{~mm}$ to $800 \mathrm{~mm}$, and groundwater salinity records across the region have ranged from less than $1000 \mathrm{EC}$ (Electrical Conductivity units) to over $13000 \mathrm{EC}$.

To consider climatic variability, the past 20 years of rainfall and potential evapotranspiration (PET) have been simulated in the hydrologic model, where the resulting flows are used as input to the salt transport model. To consider the groundwater salinity variability, three different scenarios have been considered; an average salinity over the 20 year period for each catchment, as well as low and high salinity scenarios. The low and high values have been estimated by assuming a normal distribution around the average value, with a coefficient of variation of $6 \%$ to determine the standard deviation, where the value of the coefficient of variation has been derived from groundwater observations in the region. Finally, the high and low salinity values for each catchment have been determined from the 5 and $95 \%$ occurrence probabilities of the normal distribution. There are many other uncertainties involved in this study, including the representation of rainfall over the region from a limited number of rainfall gauges (Figure 1), uncertainties in the rating curves used to derive streamflow for model calibration, as well as uncertainties in the runoff model structure and parameter values, which are acknowledged but not considered explicitly in this study.

\section{ANALYSES CONDUCTED}

Two aims have been assessed in this study. Firstly, the optimal regulator settings to deliver water of different maximum salinity thresholds to each target wetland in each year (May to April) have been identified, where each year is used to represent a different potential rainfall and PET scenario. Secondly, relationships between rainfall and the volume available to a wetland for a given maximum salinity threshold have been derived, for the optimal regulator settings for that wetland, considering the uncertainty in the relationship, as well as in the groundwater salinity. Maximum salinity thresholds have been considered starting at $2000 \mathrm{EC}$, in steps of $2000 \mathrm{EC}$, up to the maximum simulated at each target wetland.

Seven regulators and six target wetlands have been considered in this study (Figure 1 and Figure 2). To determine the optimal regulator settings to deliver water to each target wetland, every combination of the regulator settings (open or closed) has been simulated, resulting in a total of 128 model configurations. While partially open regulators can be implemented in practice, this has not been considered as part of this study. A 20 year period from May 1990 to April 2010 has been simulated for each regulator setting, to investigate the impact of climate on the performance of the different regulator settings.

The regulator configuration resulting in the greatest volume diverted to each target wetland for each maximum salinity threshold has been evaluated to estimate the volume available based on the rainfall each year. Winter rainfall was selected as the independent variable, as it was most correlated with the simulated volume, as rainfall over the summer months generally results in limited runoff. In this case, the winter rainfall is defined as the months where rainfall exceeds PET, which are May to September, inclusive.

Hyperbolic tangent equations were considered initially to relate rainfall to volume, as this functional form is often used to represent the relationships between rainfall and runoff. Both tanh relationships and linear 
relationships were calibrated to the volumes for each maximum salinity threshold that resulted in some volume delivered to a target wetland, it was found that that the linear relationship produced an average RMSE $11 \%$ lower than that obtained using the tanh relationship. Hence, linear relationships have been used in the remainder of this work.

Robust linear regression using iteratively re-weighted least-squares was used to fit the relationships, using a bi-square weighting function and tuning constant of 4.685. This approach was used due to the significant scatter in the simulated volumes, where the robust reweighting is used to avoid the tendency of the least squares approach to fit to the largest residuals between the data and the regression, which can be unrepresentative of the underlying relationship. Regression prediction confidence intervals for the $95^{\text {th }}$ percentile were computed based on the residual errors and the covariance matrix for coefficient estimates.

EWRs for priority wetlands in the South East of South Australia have been previously defined (Ecological Associates, 2009) and refined (Department for Water, 2010) based on expert knowledge. Considering Tilley Swamp as an example, it is desirable to fill the wetland to $0.7 \mathrm{~m}$ deep for two months each year, and to fill the wetland to a depth of $0.9 \mathrm{~m}$ with a frequency of 1 in 3 years. Based on the DEM for the region, this corresponds to approximately 4100 megalitres (ML) to fill the wetland to $0.7 \mathrm{~m}$ and $8200 \mathrm{ML}$ to fill the wetland to $0.9 \mathrm{~m}$. Salinity targets are also specified, where there is a target salinity of less than 5,000 EC, with an acceptable range of $3000-22000 \mathrm{EC}$. The results presented in this work are used to determine the likelihood of meeting the specified requirements.

\section{RESULTS AND DISCUSSION}

\subsection{Optimal Regulator Settings}

There was little variation in the combination of regulator settings that resulted in the maximum volume delivered to each target wetland, over each year or each maximum salinity threshold considered. The results indicated that the greatest volume for each maximum salinity threshold could be achieved by setting the regulators to divert all water possible to the target wetland. The exception to this was Mandina Marshes, where for maximum salinity thresholds of $6000 \mathrm{EC}$ and $8000 \mathrm{EC}$, larger volumes of could be achieved by diverting water in the drain of salinity higher than the maximum salinity threshold around the target wetland, and leaving the fresher watercourse water to fill the wetland.

It is desirable to determine regulator configurations that can benefit the overall health of the region, rather than target only individual wetlands. The operation of three upstream regulators (bottom of Figure 2) did not significantly influence the volumes delivered to the four downstream wetlands, and hence these regulators can generally be set to divert water to the local wetlands of Tatiara and the Bakers Range. This result was due to channel losses along the drainage network, and local catchment contributions outweighed those made by water delivered by the drainage network after the losses involved in traversing $60 \mathrm{~km}$ through open channels were considered. Further downstream, each of the four target wetlands were in competition for the available water, and hence the best regulator settings should be evaluated each year based on the target wetland with the greatest water requirement, for example the wetland that has been driest for the longest time.

\subsection{Water Yield Assessment}

The results obtained in relation to water yield assessment can be seen in Figure 3 for two of the six target wetlands considered. Across all target wetlands, generally there was an x axis intercept of around $250-300$ $\mathrm{mm}$ of winter rainfall before any water can be expected to be available for diversion. The slope of the regression line represents the volume that can be expected per $\mathrm{mm}$ of rainfall beyond this threshold rainfall. As the regulator configuration considered in this analysis was the one that maximised the volume diverted for each salinity threshold, the relationship assumes that the regulators are set to divert all water directly to the wetland of interest. The results indicate that higher volumes can be diverted if the salinity threshold is increased, and generally there is a salinity gradient from South to North in the region.

The impact of varying the groundwater salinity input to the salt transport model can be seen in Figure 4, again for two of the six target wetlands. The solid line in Figure 4 is the same linear relationship seen in Figure 3, where in Figure 4 the dashed lines represent the linear relationship fitted to the volumes simulated using both the lower and higher groundwater salinity inputs. The variation in the groundwater salinity was found to have a large impact on the lowest salinity thresholds, with large variation in the volumes simulated for thresholds of less than 6000 EC at Mandina Marshes, and less than 10000 EC at Tilley Swamp. However, for the highest maximum salinity threshold, the impact of groundwater salinity was minimal, with very tight bounds between linear relationships fitted to each groundwater concentration considered. 


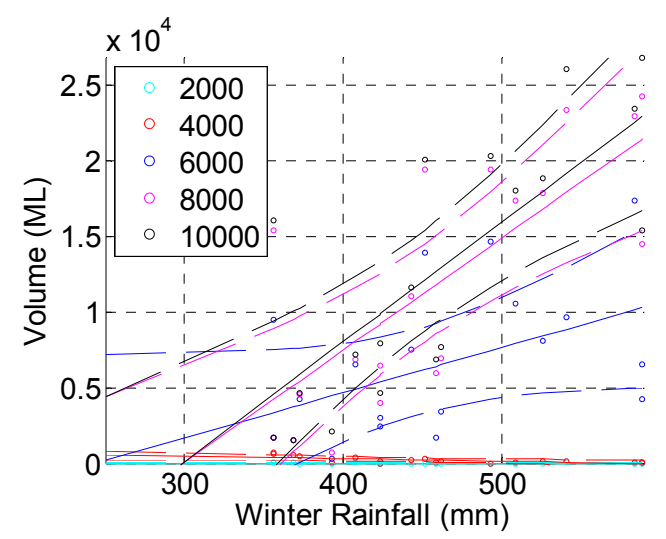

(a) Mandina Marshes

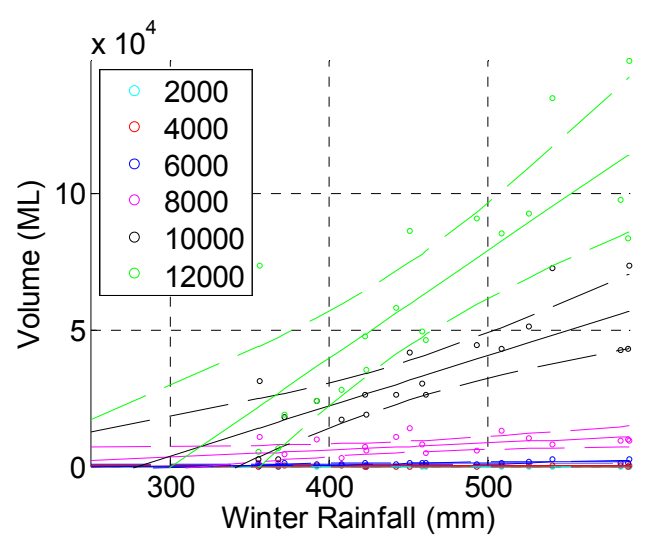

(b) Tilley Swamp

Figure 3. Deliverable volumes for different salinity thresholds (EC). Scatter plots represent annual volumes simulated at each location for each salinity threshold, solid lines a linear regression fitted between the winter rainfall and volume, and dashed lines the $95 \%$ confidence limits.

\subsection{Environmental Targets}

For the example EWR outlined in Section 4 for Tilley Swamp, the results indicate that it will be difficult to meet the target salinity of $5000 \mathrm{EC}$, with very little water available with salinity less than $8000 \mathrm{EC}$ (Figure $3(\mathrm{~b})$ ). However, even the maximum salinity simulated (12000 EC) is well below the highest value in the tolerable range (22000 EC). Based on the 12000 EC relationship in Figure 3(b), a winter rainfall between 345 and $445 \mathrm{~mm}$ is expected to deliver this volume with $95 \%$ confidence, with a winter rainfall of $400 \mathrm{~mm}$ most likely to deliver the $4100 \mathrm{ML}$ required to fill the wetland to a depth of $0.7 \mathrm{~m}$. For the 1 in 3 year event, a rainfall of $510 \mathrm{~mm}$ is required with $95 \%$ confidence bounds between 470 and $570 \mathrm{~mm}$. From Figure 4(b), it can be seen that the groundwater salinity has a minimal effect on the volume simulated for this highest salinity threshold. The occurrence of rainfall events generally supports the ability of the system to deliver the required volumes with a frequency of 1 in 3 years, as 6 of the 20 scatter points for the $12000 \mathrm{EC}$ threshold are at or above the volume required to fill the wetland to $0.9 \mathrm{~m}$. It should also be noted that the $12000 \mathrm{EC}$ in this case is the upper limit, which includes all fresher volumes simulated, and assumes that all regulators are set to divert all runoff directly to this wetland.

Based on the results presented, the target salinities specified by current EWRs are generally unlikely to be delivered, as very little water of salinity less than $4000-6000 \mathrm{EC}$ was simulated. Goodman et al. (2010) found that aquatic species could safely tolerate $8000 \mathrm{mg} / \mathrm{L}$ (approximately $13500 \mathrm{EC}$ ) much higher than the specified target salinities, suggesting that more saline water may be able to be diverted to the wetlands. However, growth rates were reduced at these salinities and lifecycle aspects, such as germination and seed setting, were not investigated. Also, there is a risk that salt will accumulate in the wetland if fresher water is not available to flush out an initial saltier diversion. Hence, further investigation on the full impacts on the use of saline water for environmental purposes is required.

\section{SUMMARY AND CONCLUSIONS}

Both water quality and quantity models have been developed for a region in the South East of South Australia to assist the water resource management for environmental outcomes. The impact of variations in climate and groundwater salinity on volumes deliverable to target wetlands was considered for a range of maximum salinity thresholds. Relationships were derived to determine the likely yield available for a given winter rainfall, as well as the rainfall corresponding to the "commence to flow" threshold for the season, to assist with the management of regulator settings for environmental purposes.

In practice, regulators settings are not fixed for a whole year, and are changed based on conditions as they unfold over the winter and spring months. This is necessary to avoid the diversion of the highest salinity runoff into wetlands with relatively freshwater ecosystems, in response to short periods of high flow events, as well as providing the ability to meet multiple objectives each year. Each of these events is difficult to accurately predict in advance due to the unknown climatic variables. However, estimates of the volume of water of different salinities that is likely to be available for target wetlands have been determined through this work, which can be used to inform the planning of system operation, as well as decisions made over shorter time periods. The relationships derived between annual volume and winter rainfall may be able to be 


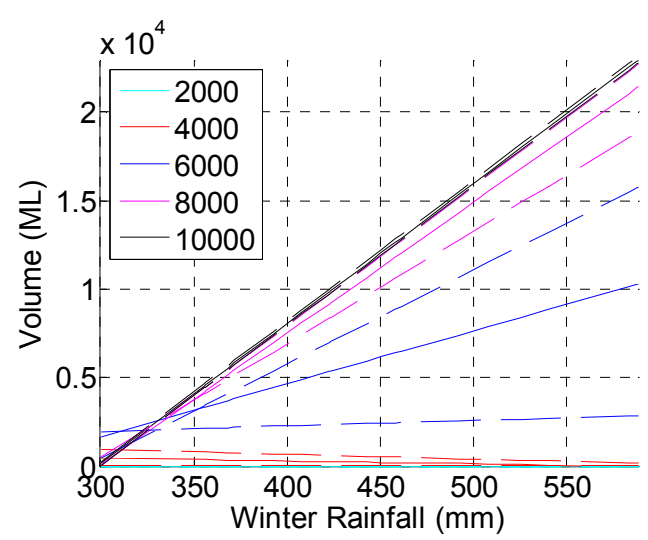

(a) Mandina Marshes

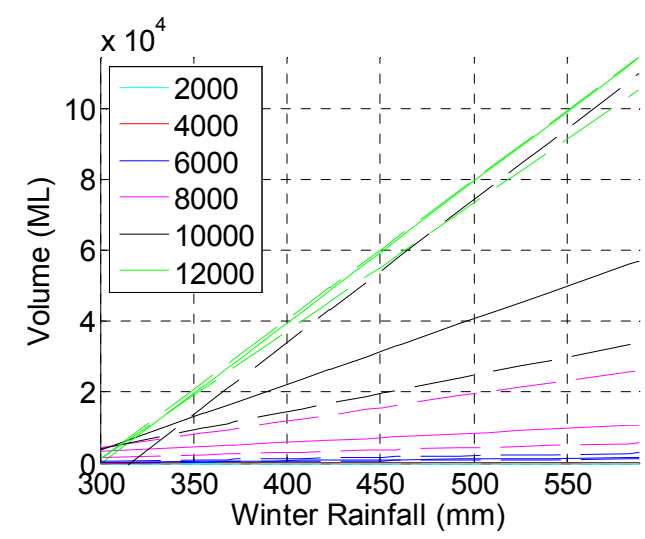

(b) Tilley Swamp

Figure 4. Impact of a range of groundwater salinity values, with solid lines based on average groundwater salinities, and dashed lines lower and upper bounds of observed groundwater salinities.

improved through the use of more complex relationships, for example, considering the timing of rainfall, as well as catchment antecedent conditions, and is the focus of further research.

\section{ACKNOWLEDGMENTS}

This work is supported by the Australian Research Council through its Linkage scheme and the South Australian Department for Water (DFW) as industry partners, as well as the Goyder Institute for Water Research. The authors would like to acknowledge the assistance of DFW staff in this work, particularly Mark deJong and Paul Masters, as well as the anonymous reviewers for their valuable comments.

\section{REFERENCES}

Coff, B. E., N. J. Ditty, M. C. Gee, J. M. Szemis, H. R. Maier, G. C. Dandy, and M. S. Gibbs (2009). Relating catchment attributes to parameters of a salt and water balance model. Paper presented at 18th World IMACS Congress and MODSIM09 International Congress on Modelling and Simulation, Cairns, Australia, Jul 13-17.

Croke, B. F. W., J. L. Ticehurst, R. A. Letcher, J. P. Norton, L. T. H. Newham, and A. J. Jakeman (2007). Integrated assessment of water resources: Australian experiences. Water Resources Management 21(1), 351-373.

Department for Water (2010). South east water science review. Lower Limestone Coast Water Allocation Plan Taskforce, Adelaide.

Department of Water Land and Biodiversity Conservation (2002). Soils of south australia's agricultural lands. Soil and Land Information, Department of Water, Land and Biodiversity Conservation, Adelaide.,

Ecological Associates (2009). Estimation of water requirements of wetlands in the south east of south australia. Department of Water, Land and Biodiversity Conservation, Adelaide, South Australia.

Gibbs, M.S., G. C. Dandy, and H. R. Maier (2010). Evaluation of parameter setting for two gis based unit hydrograph models. Journal of Hydrology 393(3-4), 197-205.

Gibbs, M.S., G.C. Dandy, and H. R. Maier (2011). Evaluating parameter sensitivity for surface water modelling of ungauged catchments. Paper presented at Proceedings of the 34th IAHR World Congress, Brisbane, Australia, 26 June - 1 July 2011.

Gibbs, M.S., A. Goodman, D.J. Partington, G.C. Dandy, and H.R. Maier (2008). Dryland salinity decision support systems in data-scarce regions. Paper presented at Water Down Under 2008, Engineers Australia, Adelaide, Australia, April 14-17.

Goodman, A. M., G. G. Ganf, G. C. Dandy, H. R. Maier, and M. S. Gibbs (2010). The response of freshwater plants to salinity pulses. Aquatic Botany 93(2), 59-67.

James, K. R., B. Cant, and T. Ryan (2003). Responses of freshwater biota to rising salinity levels and implications for saline water management: A review. Australian Journal of Botany 51(6), 703-713.

Tuteja, N. K., G. Beale, W. Dawesc, J. Vaze, B. Murphy, P. Barnett, A. Rancic, R. Evans, G. Geeves, D. W. Rassam, and M. Miller (2003). Predicting the effects of landuse change on water and salt balance - a case study of a catchment affected by dryland salinity in nsw, australia. Journal of Hydrology 283(1-4), 67-90. 